\title{
Evaluation questionnaires for CIMOSA
}

\author{
Task Force
}

11.1 ARCHITECTURE $^{1}$ (All answers in italics)

\subsubsection{Users of the architecture}

What is the intended/targeted audience of this architecture?

No answer provided

\subsubsection{Intended scope of architecture}

Please check those activities which are in the intended scope of the architecture (in the short term, i.e. 2-3 years)

\begin{tabular}{|c|c|c|c|}
\hline $\begin{array}{c}\text { [] } \\
\text { covered } \\
\text { context }\end{array}$ & $\begin{array}{c}\text { partially cov- } \\
\text { ered context }\end{array}$ & $\begin{array}{c}\text { context not } \\
\text { covered }\end{array}$ & $\begin{array}{c}{[]} \\
\text { no } \\
\text { information }\end{array}$ \\
\hline
\end{tabular}

Example

[x] [ ] [ ] [ ] product research and development

[ ] [ ] [ ] [x] customer services, product maintenance

[ ] [ ] [ ] [x] product management, marketing function, strategic

$[\mathrm{x}][\mathrm{]}][\mathrm{]}]$ product distribution

[ ] [ ] [ ] [x] marketing

$[\mathrm{x}][\mathrm{]}][\mathrm{]}] \mathrm{]}$ product design

$[\mathrm{x}][\mathrm{]}[\mathrm{]}[\mathrm{]}$ production planning

$[\mathrm{x}][\mathrm{]}] \mathrm{]}] \mathrm{]}$ manufacturing control

$[\mathrm{x}][\mathrm{]}] \mathrm{]}[\mathrm{]}$ manufacturing

[x] [ ] [ ] [ ] material handling, storage and transport

1. Questionnaire filled in by Peter Bernus based on Questionnaire Version 2; answers provided by Ing. Jakob Vlietstra, and information provided at the Melbourne Task Force Meeting by Ing. Dick Zoetekouw (May 1992) 
$[\mathrm{x}][\mathrm{]}[\mathrm{]}[\mathrm{]}$ testing and quality control

[x] [ ] [ ] [ ] logistics

[ ] [ ] [ ] [x] acquisition

[ ] [ ] [ ] [x] legal services

[ ] [ ] [ ] [x] personnel services finance, accounting

[ ] [ ] [ ] [x] infrastructure, archiving and library services

[ ] [ ] [ ] [x] infrastructure, communications (excluding computer communications)

[x] [ ] [ ] [ ] information technology infrastructure, including computer communications, computing, database management, etc.

[ ] [ ] [ ] [x] education

[ ] [ ] [ ] [x] strategic enterprise management

[ ] [ ] [ ] [x] market research

[x] [ ] [ ] [ ] resource management

[x] [ ] [ ] [ ] factory development/development of the production facility)

[ ] [ ] [ ] [x] project management

$[\mathrm{]}[\mathrm{x}][\mathrm{]}] \mathrm{]}$ factory design

$[\mathrm{]}[\mathrm{x}][\mathrm{]}] \mathrm{]}$ factory building and modernization

[ ] [x] [ ] [ ] factory maintenance

$[\mathrm{C}][\mathrm{x}][\mathrm{]}$ infrastructure, energy

[ ] [x] [ ] [ ] infrastructure, buildings and grounds

[ ] [x][ ] [ ] other (please specify)

\subsubsection{What is the highest intended level of genericity on which this architecture is applicable? (check one)}

[ ] every type of enterprise

[x] certain type of industry (please specify which one)?

Continuous: steel, paper;Manufacturing: discrete part (electric, electromechanical, aerospace) Note: the architecture may be applicable to all types of enterprises.

What is the area of industry in which the architecture has already been applied? discrete part manufacturing 
11.1.4 Which stage of systems development is addressed by the architecture? (multiple choice question)

\begin{tabular}{|c|c|c|c|}
\hline $\begin{array}{l}{[] \text { fully }} \\
\text { covered }\end{array}$ & $\begin{array}{c}{[] \text { partially }} \\
\text { covered }\end{array}$ & {[] not covered } & $\begin{array}{c}{[] \text { no }} \\
\text { information }\end{array}$ \\
\hline
\end{tabular}

Example

$\begin{array}{ll}[\mathrm{x}][\mathrm{]}][]] & \text { requirements } \\ {[\mathrm{x}][][][]} & \text { implementation (configuration and reconfiguration) } \\ {[\mathrm{x}][\mathrm{C}][\mathrm{C}} & \text { design } \\ {[\mathrm{x}][][][]} & \text { operation and maintenance }\end{array}$

\subsubsection{What are the goals which we would like to attain by developing generic CIM architectures? (Which are the main factors of industry's need?)}

(Please concentrate on the user requirements of a prospective utilizing industry.)

\begin{tabular}{|c|c|c|c|}
\hline $\begin{array}{c}\text { [] essential } \\
\text { factor }\end{array}$ & $\begin{array}{c}\text { [] important } \\
\text { factor }\end{array}$ & $\begin{array}{c}{[] \text { advantageos }} \\
\text { but not essential }\end{array}$ & $\begin{array}{c}{[] \text { not }} \\
\text { important }\end{array}$ \\
\hline
\end{tabular}

Example

[ ] [ ] [x] [ ] better use of current resources

$[\mathrm{x}][$ ] [ ] [ ] integration of current technology

[x] [ ] [ ] [ ] cutting excessive costs of having to develop CIM systems individually

[ ] [ ] [x] [ ] improve the quality of the developed individual systems/ manufacturing systems/CIM systems,etc.

[x] [ ] [ ] [ ] enabling the development of a marketplace for compatible CIM products

[x] [ ] [ ] [ ] obtain flexibility in system and adaptation to change in requirements

\subsubsection{De facto scope and detail}

This question is about how completely the architecture has been defined relative to its intended scope (see Question 2) and its intended detail.

You will have by now a few projects which have already used one part or another of this architecture. We would like to have a list of those activities which were covered by these projects and see what is the level of maturity of the models available (industry mature models, feasibility tested models of individual systems, developed generic models)

Individual case studies - AT\&T Network Cable Systems 
Development (function, information)

Manufacturing (function, information, resources)

Logistics (function, information, resources)

Manufacturing control - FIAT (FMS)

$V W$ (shop floor control)

Resource management - Bull

IT infrastructrue (communication services, front end services) (+ many other case studies)

Partial models - SW house + University project

(Computer aided enterprise engineering environment/tool) .

Generic models - Fiat \& Renault

Enterprise requirements (function, information, resource)

Enterprise system design (function, information).

Enterprise system implementation (function, information)

[The answers given at the time of filling in the questionnaire were not clear with regard to the maturity of the models developed. The Esprit VOICE projects (I and II) were started to validate the CIMOSA modelling framework in various industries]

\subsubsection{Omissions}

(a) Please check and give details if needed:

[x] the architecture covers its promised intended scope

[ ] the architecture omits some necessary detail (please specify the additional detail the architecture should provide)

(b) If you indicated a need for extension, could you name here any other architecture and model which does cover the missing detail (give specifics) (Note [Bernus]) In face of the Melbourne Task Force Meeting we should have a mapping between CIMOSA-Purdue-GRAI identifying hitherto unknown missing context/detail (E.g., modelling of the "enterprise building" process).

\subsubsection{Redundancy}

Does this architecture require that existing standards must be rewritten (e.g. expressed in a new form without changing the content) in order to fit this architecture?

The architecture is a genuine framework, so constructs and elements which are not part of it have to be modified in order to fill the 
framework. This work is currently in development for certain levels (design and implementation). However, CIMOSA policy is to adopt existing standards where applicable.

\subsubsection{System extensibility}

How do you ensure that systems created according to this architecture are open ended?

Existing systems are taken into account in the System Life Cycle by means of a kind of reverse engineering. Thus the modelling framework is filled as if it was a newly designed system. The methodology is both for building new systems and integrating existing ones.

If you judged that the architecture allows modular evolution, is this judgement based on

[x] theoretical considerations

[x] feasibility study or pilot project

[ ] repeated industry experience

\subsubsection{Resilience}

Does the architecture provide any principles or guidance that will help the user to limit the effect of imposed external changes on the operation of the system?

In terms of application and IT changes (e.g. reconfiguration), and changes in the control flow, the architecture is very adaptable. Similar to the Purdue Architecture there is a separation of function and control. This is the main motivation for distinguishing between "Enterprise Activities" (that describe functionality) and "Business processes" (that describe control by means of "Procedural Rule Sets").

\subsubsection{Skills required to implement}

Does the architecture adequately treat the skills required by the user to allow for the design and building of a specific system described by it? (give rating):

[x] $\operatorname{good}^{\mathrm{a}}$

a.The architecture is very good from this respect if the skills required are available or there are tried and natural, pragmatic ways for practitioners to extend their skills in the new direction. 
(Note by Bernus) This experience is drawn from electronic discrete part manufacturing. It appears that process industries and discrete part mechanical manufacturing have a different skill base/subculture. This question needs further consideration.

To put it in another way: the electronic industry is more receptive of formal methods/computer science concepts than the rest. It appears that explaining CIMOSA in the Purdue way could make an impact in other industries.

\subsubsection{Dependence on new technologies}

Does the implementation of this architecture require a given type of new technology for any application within the scope? (A technology is new in this respect if it has not yet been proven under industrial circumstances?)

[ ] no new technology required

[x] yes (please specify what new technology is involved) e.g.

[x] distributed relational databases

[x] distributed object oriented databases

[x] OSI communication

[x] Open Distributed Processing Platform

[x] others (please specify) Client server technology

(Note by Bernus) Although other architectures answered ' $n o$ ', the fact will probably be that they will be materialized on the basis of these new technologies anyway - Therefore the 'yes' answer is not a limitation to the applicability in the manufacturing enterprise.

\subsubsection{What is your opinion about the future prospects for this archi- tecture?}

\begin{tabular}{|c|c|c|c|}
\hline[] & {[]} & {[]} & {[]} \\
yes, widespread & yes, limited area & no & undecided \\
\hline
\end{tabular}

Example

[][][]$[x]$

will have theoretical impact

$[\mathrm{c}][\mathrm{x}][\mathrm{]}] \mathrm{]}]$ will gain industry acceptance in the present form

$[\mathrm{x}][][\mathrm{]}][\mathrm{]}$ will gain industry acceptance in developed (or modified) fo $[\mathrm{x}][][][]$ other (please specify) will set standards 
11.1.14 What were the reasons for the development of this architecture?

\begin{tabular}{|c|c|c|c|}
\hline $\begin{array}{c}\text { main } \\
\text { reason } \\
{[]}\end{array}$ & cofactor & $\begin{array}{c}\text { not a known } \\
\text { reason } \\
{[]}\end{array}$ & no information \\
\hline
\end{tabular}

Example

[ ] [x] [ ] [ ] utilization in a given segment of industry

[ ] [x] [ ] [ ] development of a national standard

[x] [ ] [ ] [ ] development of an international standard

[ ] [x] [ ] [ ] utilization by a given firm

[ ] [x] [ ] [ ] utilization by a group of firms

[ ] [ ] [x] [ ] utilization for teaching purposes

[ ] [ ] [x] [ ] utilization for research purposes (Other, please specify)

[x] [ ] [ ] [ ] (Other please specify): support integration

[x] [ ] [ ] [ ] Provide Europe with a competitive technology

11.1.15 What is the driving force behind this architecture?

\begin{tabular}{|c|c|c|c|}
\hline $\begin{array}{c}{[]} \\
\text { main reason }\end{array}$ & $\begin{array}{c}{[]} \\
\text { cofactor }\end{array}$ & $\begin{array}{c}{[] \text { not a known }} \\
\text { reason }\end{array}$ & $\begin{array}{c}{[] \text { no }} \\
\text { information }\end{array}$ \\
\hline
\end{tabular}

[x] [ ] [ ] [ ] technology pull (there was a perceived need in industry for which the generic architecture intends to be the answer)

[x] [ ] [ ] [ ] technology push (results in the area of architectures methodologies, information technology, communications manufacturing technology created opportunity or incentive for industry to develop this generic CIM architecture)

Please expand your views on the above question if possible.

To provide solutions for the business needs for adapting to changes (internal and external) through system flexibility.

\subsubsection{Adequacy}

Please rate the adequacy of the architecture with respect to the help which it provides for attaining the essential or important goals which you identified in Question 5.

\begin{tabular}{|c|c|c|c|c|}
\hline poor & average & good & excellent & no info. \\
{[]} & {[]} & {[]} & {[]} & {[]} \\
\hline
\end{tabular}

Example

[ ] [ ] [x] [ ] [ ] better use of current resources

[ ] [ ] [ ] [x] [ ] integration of current technology 
[ ] [ ] [ ] [x] [ ] cutting excessive costs of having to develop CIM systems individually

[ ] [ ] [x] [ ] ] improve the quality of the developed individual systems/ manufacturing systems/CIM systems etc.

[ ] [x] [ ] [ ] [ ] enabling the development of a marketplace for compatible CIM products

[ ] [ ] [x] [ ] [ ] obtain flexibility in system configuration and adaptation to change in requirements

What is the main strength of this architecture?

- Providing an overall framework supporting engineering and operation (build and runtime);

- Promoting standardization and standards

- Enabling enterprise modelling;

- Providing enterprise operation flexibility

To your knowledge which essential or important goals (see Question 5) are specifically not adequately addressed by this architecture? no answer provided

\subsection{MODELLING}

\subsubsection{What kinds of models describe this architecture?}

Please characterize the models which this architecture requires to be produced? (The table for your answers has been broken into four parts because it had too many columns - see following pages).

Characterize the corresponding modelling languages used to express the models. NB. For the purposes of collecting information we have ordered these tables by the models and not by the modelling languages. Note, that because the same modelling language is often used for more than one model, it is enough to characterize the language only once. However, it is expected that the questions about the language's adequacy for each separate type of model will be answered separately.

Important: the descriptions capturing requirements, designs, etc, are produced in many, very different forms (formal mathematical models, graphs, natural language, tables). We use the word 'model' to refer to all of these forms. 


\begin{tabular}{llllll}
\hline Model $^{\mathrm{a}}$ & $\begin{array}{l}\text { Modelling } \\
\text { Language }^{\mathrm{b}}\end{array}$ & $\begin{array}{l}\text { Degree of } \\
\text { formality }^{\mathrm{c}}\end{array}$ & $\begin{array}{l}\text { Should it be } \\
\text { executable? }\end{array}$ & $\begin{array}{l}\text { Is it exe- } \\
\text { cutable? }\end{array}$ & $\begin{array}{l}\text { Demonstra- } \\
\text { ted feasibil- } \\
\text { ity }\end{array}$ \\
\hline $\mathrm{R}^{\mathrm{e}}$ & constructs $^{\mathrm{f}}$ & $\mathrm{I} \rightarrow \mathrm{S}^{\mathrm{g}}$ & partly $\mathrm{Y}$ & $\mathrm{N} \rightarrow \mathrm{Y}$ & no \\
\hline $\mathrm{D}^{\mathrm{h}}$ & constructs $^{\mathrm{i}}$ & $\mathrm{I}$ & $\mathrm{Y}$ & not yet & no \\
\hline $\mathrm{I}^{\mathrm{j}}$ & constructs $^{\mathrm{k}}$ & $\mathrm{S}^{\mathrm{g}}$ & $\mathrm{Y}$ & not yet & no \\
\hline
\end{tabular}

a. Please add rows as necessary. E.g., 'functional requirements model,' 'organizational design model', etc. Note that if models are substantially different on various levels of genericity then you are asked to enter these as separate models.

b. Here 'language' is used in general sense, e.g., ER, Lotos, IDEF0, natural language, Petri net, etc.

c. Please rate: $\mathrm{I}=$ Informal, $\mathrm{S}=$ Structured but the expressive power of the formal part is not adequate (missing information being added in natural language), $\mathrm{F}=$ Formal mathematical model, with formal semantics

$\mathrm{d}$. This is the feasibility of producing an adequate model using this language, $\mathrm{P}=$ Practically demonstrated, $\mathrm{T}=$ Demonstrated in theory, or only $\mathrm{C}=$ Conjectured. Please add further comments in footnotes and on separate pages if necessary.

e. Requirements Specification Model

f. For function/information/resource/organization view respectively IDEF0 + CSP/ERA/-(not yet decided)

g. The CIMOSA Cube with its dimensions

- function/information/resource/organizational views

- requirements/design/implementation

- generic/partial/particular models

h. Design Specification Model

i. Languages on all three levels are similar

j. Implementation Description Model

$\mathrm{k}$. At the moment one language is defined on each level, but the number of languages is still open.

The Information Integration Infrastructure is modelled in LOTOS

\begin{tabular}{lll}
\hline Model & $\begin{array}{l}\text { Adequacy of } \\
\text { modelling language }\end{array}$ & $\begin{array}{l}\text { Is there any related } \\
\text { modelling language? }\end{array}$ \\
\hline $\mathrm{R}$ & $\mathrm{G} \rightarrow \mathrm{V}$ & see note f previous table \\
\hline $\mathrm{D}$ & $\mathrm{G}$ & see note i previous table \\
\hline $\mathrm{I}$ & $\mathrm{G}$ (to be further developed) & see note $\mathrm{k}$ previous table \\
\hline
\end{tabular}


a.P = Poor, $\mathrm{A}=$ Adequate, $\mathrm{G}=\mathrm{Good}, \mathrm{V}=$ Very good; please comment on problems, limitations in footnote if needed. E.g., overformalized, not formal enough, certain detail not expressible, forces unnecessary decision to be taken too early, etc.

b.If the language used is not a standard and there is a related standard, could you comment, in a footnote, why the selected language is used instead of a standard one?

In all modules, it is believed that the information to be recorded in these models is available and that the languages selected are semantically adequate

\begin{tabular}{lllll}
\hline Model $^{\mathrm{a}}$ & $\begin{array}{l}\text { Verifiability } \\
\text { of model }\end{array}$ & $\begin{array}{l}\text { Could any } \\
\text { alternative lan- } \\
\text { guage be used? }\end{array}$ & $\begin{array}{l}\text { Can } \\
\text { completeness } \\
\text { be achieved? }\end{array}$ & $\begin{array}{l}\text { Supported by } \\
\text { CASE tool? }\end{array}$ \\
\hline $\mathrm{R}$ & $\mathrm{VH} \rightarrow \mathrm{VE}$ & no & $\mathrm{N}$ & $\mathrm{Y}^{\mathrm{e}}$ \\
\hline $\mathrm{D}$ & $\mathrm{VE}$ & no & $\mathrm{N}$ & $\mathrm{N}$ \\
\hline $\mathrm{I}$ & $\mathrm{VE}^{\mathrm{f}}$ & no & $\mathrm{N}^{\mathrm{g}}$ & $\mathrm{N}$ \\
\hline
\end{tabular}

a. Please add rows as necessary.

b. Rate: VH = model verifiable by human expert, following a method; VA =automatic or interactive verification is possible; $\mathrm{VK}=$ automatic or interactive verification is possible if large knowledge base present; $\mathrm{VE}=$ validation possible only by experiments (real or simulation).

c. $\mathrm{Y}=$ yes, a complete mathematical model can be developed from which all the necessary design features can be calculated, $\mathrm{N}=$ no, - if not, could you tell in a footnote what provision can be made to substitute for the lack of mathematical completeness?

d. Please provide names of CASE tools (or write $Y=y e s$ if name is unknown to you), $N=$ no, $U=u n k n o w n$ (no information). Note that question 20 will separately ask about the adequacy of the CASE/CAE tools listed.

e. VE is a developed version with simulation for qualification and for release to operation control and manufacturing.

f. CASE Tools for Requirements level are available.

g. Use of simulation to qualify the model.

Due to the size of the models support by CASE tools for verification is needed. 


\begin{tabular}{lll}
\hline Model $^{\text {a }}$ & $\begin{array}{l}\text { Adequacy of language for people } \\
\text { who should use/interpret the } \\
\text { model }^{\text {b }}\end{array}$ & $\begin{array}{l}\text { Adequacy of language for those } \\
\text { who should produce the model }\end{array}$ \\
\hline R & A & A \\
\hline D & A & A \\
\hline I & A & A \\
\hline
\end{tabular}

a. Please add rows as necessary.

b. Please rate the modelling language $P=$ poor, $A=$ adequate, $G=$ good, $V=$ very good; please comment on problems, limitations in footnote if needed.

c. Please rate the modelling language $P=$ poor, $A=$ adequate, $G=$ good, $V=$ very good; please comment on problems, limitations in footnote if needed.

Due to the size of models CASE tools for the production and interpretation of models are needed. (Note [Bernus]: the original answer by CIMOSA in the table used the word 'compliance' instead of adequacy. Also the CIMOSA answer points out that the CIMOSA languages were designed for end users / business professionals).

\subsubsection{How well does the architecture describe the operational characteristics of an enterprise in contrast with describing only its basic design feature?}

[x] operational characteristics can be explicitly specified

[x] operational characteristics can be derived from the design

features (e.g. through simulation model)

\subsubsection{Formalism}

Do you think formal methods (with rigorously defined syntax and semantics) are needed to describe and interpret the architecture under discussion and the representation of particular systems by it?

[ ] necessary

[ ] desirable

[x] possible but limited to design and implementation models

[ ] not possible 
Please comment on what areas you have applied or intend to apply formal methods?...

(Comment [Bernus]): The formal character of the languages should not necessarily be visible to the users. What they see is an ordinary programming language on the Implementation Description level. The formalization takes place at the meta level guaranteeing that the standard excludes misinterpretations and ambiguities.

Could there be a formal canonical view developed together with a modelling language which would subsume all of the ones used? If yes, please specify what should be the characteristics of such a language:

An architecture designed for managing change is hardly conceivable in a canonical form, it must be left open to incorporate user constructs and new business strategies.

Do you think that the scope of the formal methods is broad enough to capture what you want to describe?

[x] no

Can people who need to deal with these models easily relate to these formalisms?

[x] yes

It appears to be that Yes is the answer, but top people are needed to carry out integration projects!

\subsubsection{Verification support}

How extensively are Computer-aided Engineering (CAE) tools available to verify the prescribed models?

[x] full support for the following models:

Requirements description (function and information view)

Do you think it is necessary to have CAE tools to support the methodology?

Full support means model management, consistency checking of models, and consistency checking between the models produced for different views and levels, and between two successive versions of a model to guarantee smooth online update to the model being executed.

[x] yes, full support is needed

Are there any limitations to achieving the above?

No answer provided 
How well can the architecture be used to verify the completeness and adequacy of the overall design for an enterprise or any of its components? (Please comment on merits and problems.)

The goal of CIMOSA is to achieve this.

\subsubsection{Economic questions}

How well does the associated methodology handle economic questions related to the enterprise described using its methods? (Give comments)

[ ] well covered

[x] some, but not full coverage of issues (what is lacking?)

[ ] not addressed in the modelling

[ ] no information

On the requirements modelling level economic questions are addressed through functional objectives and constraints.

\subsection{METHODOLOGY}

\subsubsection{Does the architecture have a methodology connected to it?}

[ ] no

[x] yes (please give the name of the methodology)

CIMOSA Systems Life cycle

If possible, can you specify what the components of the methodology are?

- Create instances of constructs $(G, P, I)$

- Derivation of models (instantiation)

- Generation of views

How complete is the methodology?

[x] this is a complete methodology, covering all aspects of enterprise engineering activity

[ ] the methodology is a collection of methods/logical techniques (but only separate methodologies are available for the individual modelling tasks)

[ ] the methodology is planned to be a complete one

(Note by Bernus) It appears that the methodological cookbook of CIMOSA has not been written yet, as identified at the Melbourne Task Force Meeting. The Purdue Architecture Mapping on/from CIMOSA or 
indirectly the "Purdue Implementation Procedures Manual" for CIMOSA would be a possible methodology.

Does the methodology address the human factor in the enterprise?

[ ] treats the necessary human organization

[ ] skill levels for operating personnel

[ ] training requirements

[ ] treats teams

[ ] treats individual workers

The human factor is described both in the Organizational View in terms of responsibilities and authorities and in the Resource View as skills. Only training is not dealt with explicitly [answer provided without reference to the above choices (Bernus)].

\subsubsection{Validation status of the methodology}

Was the methodology validated

[ ] in implemented industry projects/systems

[x] in experimental systems

[x] other: (Could you give references?) Case studies

References: Contracts - Fiat, Aerospatial, AT\&T, Renault, Cap Gemini, NLR,ITGEM,WZL Aachen, etc.

\subsubsection{Maturity of the methodology}

The methodology ${ }^{1}$ has been

[x] successfully taught by others than its developers

[x] successfully applied by other than its developers

[x] repeatedly applied by its developers

[x] shown to work by its developers

[ ] other (e.g. 'under development')

Being taught to University students at TH-Aachen

1. Note [Bernus] as a result of this questionnaire the Task Force had realised how ambiguous the term 'methodology' is in industry. In some cases, like in the answer given here, it means the availability of a modelling framework, in some others it means the availability of detailed work instructions. The distinctions will be dealt with in the matrix mapping of methodologies in this book. 


\subsubsection{Scope of the methodology}

\begin{tabular}{|c|c|c|c|c|}
\hline $\begin{array}{c}\text { [] extensive } \\
\text { coverage }\end{array}$ & $\begin{array}{c}{[] \text { some }} \\
\text { coverage }\end{array}$ & $\begin{array}{c}{[] \text { no }} \\
\text { coverage }\end{array}$ & $\begin{array}{c}{[] \text { no }} \\
\text { information }\end{array}$ & $\begin{array}{c}{[] \text { not }} \\
\text { applicable }\end{array}$ \\
\hline
\end{tabular}

Check appropriate fields of the table.

\begin{tabular}{|c|c|c|c|}
\hline $\begin{array}{l}\text { Activities and } \\
\text { related } \\
\text { methods to }\end{array}$ & $\begin{array}{l}\text {...common to all } \\
\text { systems in the } \\
\text { scope }\end{array}$ & $\begin{array}{l}\text {...common to a } \\
\text { family of systems } \\
\text { in the scope } \\
\text { (which one?) }\end{array}$ & $\begin{array}{l}\text {...of individual } \\
\text { systems }\end{array}$ \\
\hline $\begin{array}{l}\text { produce } \\
\text { requirements... }\end{array}$ & {$[\mathrm{x}][\mathrm{]}][\mathrm{]}] \mathrm{]}[\mathrm{]}$} & [x] [ ] [ ] [ ] [ ] & {$[x][][][][]$} \\
\hline $\begin{array}{l}\text { produce the } \\
\text { design } \\
\text { specifications... }\end{array}$ & $[\mathrm{x}][\mathrm{]}][\mathrm{]}] \mathrm{]}]$ & [x] [ ] [ ][ ] [ ] & {$[x][][][][]$} \\
\hline $\begin{array}{l}\text { produce the } \\
\text { detailed design... }\end{array}$ & $[\mathrm{x}][\mathrm{]}][\mathrm{]}] \mathrm{]}]$ & {$[\mathrm{x}][\mathrm{]}][][\mathrm{]}] \mathrm{]}$} & $[\mathrm{x}][\mathrm{]}] \mathrm{]}][\mathrm{]}]$ \\
\hline $\begin{array}{l}\text { produce the } \\
\text { system... }\end{array}$ & {$[\mathrm{]}[\mathrm{x}][\mathrm{]}][\mathrm{]}]$} & {$[\mathrm{]}[\mathrm{x}][\mathrm{]}][\mathrm{]}] \mathrm{]}$} & {[]$[x][][][]$} \\
\hline $\begin{array}{l}\text { produce the } \\
\text { operational and } \\
\text { maintenance } \\
\text { methods.... }\end{array}$ & $[\mathrm{x}][\mathrm{]}][\mathrm{]}] \mathrm{]}]$ & {$[x][][][][]$} & $[\mathrm{x}][\mathrm{]}] \mathrm{]}][\mathrm{]}] \mathrm{]}$ \\
\hline
\end{tabular}

E.g. check 'extensive coverage' box in upper right hand corner if the methodology extensively tackles 'activities and related methods to produce the requirements of individual systems,' to be read from the table as:

Activities and related

methods to

produce the requirements ......of individual systems.

Note 1: If the methodology is partially complete in any of these respects pleased add footnote to the box you checked.

Note 2: You can add additional model types below, or on a separate sheet, if you feel that the above categories are not exhaustive: 


\subsubsection{Presentation of the methodology}

\begin{tabular}{|c|c|c|c|c|c|c|}
\hline $\begin{array}{c}{[]} \\
\text { extensive } \\
\text { planned }\end{array}$ & $\begin{array}{c}{[]} \\
\text { some } \\
\text { planned }\end{array}$ & $\begin{array}{c}{[]} \\
\text { extensive } \\
\text { now }\end{array}$ & $\begin{array}{c}{[]} \\
\text { some now }\end{array}$ & $\begin{array}{c}{[]} \\
\text { none }\end{array}$ & $\begin{array}{c}{[]} \\
\text { no info. }\end{array}$ & $\begin{array}{c}{[]} \\
\text { not } \\
\text { applicable }\end{array}$ \\
\hline
\end{tabular}

[ ] [ ] [x] [ ] [ ] [ ] [ ] handbook or collection of handbooks

[ ] [ ] [ ][x][ ][ ][ ] teaching material

[ ] [ ] [ ] [ ] [ ] [x][ ] organizational procedures

[ ] [ ] [ ] [ ] [ ] [x] [ ] CASE tool support for individuals

[ ] [ ] [x][ ][ ] [ ] [ ] project database

[ ] [ ] [x] [ ] [ ] [ ] [ ] CASE tool support for project team

Other form: A PC based Storyboard system is available

that helps understand CIMOSA.

\subsubsection{Genericity}

We want to know how big the gap is between the methodology as presented (see Question 26) and the way it is applied in particular projects.

[x] the methodology describes general procedures only

[x] the methodology is supported by a collection of application examples / cookbook

(Case studies are available) [Note (Bernus): the answers seem a little optimistic. Question: Are there paradigmatic example cases developed to form a cookbook? I propose to say "some individual case studies are available for use."]

\subsubsection{Quality of the methodology}

Please rate the methodology from the following aspects:

\begin{tabular}{|c|c|c|c|c|c|}
\hline $\begin{array}{c}\text { poor } \\
{[]}\end{array}$ & average & good & excellent & no info. & N/A \\
{[]} & {[]} & {[]} & {[]} & {[]} \\
\hline
\end{tabular}

[ ] [ ] [x] [ ] [ ] [ ] [ ] support of cooperative teamwork

[ ] [ ] [ ] [ ] [x] [ ] [ ] support of work with multiple organizations

[ ] [ ] [ ] [x] [ ] [ ] [ ] flexibility in terms of project size

[ ] [ ] [x] [ ] [ ] [ ] [ ] flexibility in terms of innovativity of project

[ ] [ ] [x] [ ] [ ] [ ] [ ] quality control of project

[ ] [ ] [x] [ ] [ ] [ ] [ ] CAE tools support 